EDITOR'S

CHOICE

\title{
What makes champions? A review of the relative contribution of genes and training to sporting success
}

Ross Tucker, ${ }^{1}$ Malcolm Collins ${ }^{2}$

'Department of Human

Biology, Exercise Science and

Sports Medicine, University of

Cape Town, Cape Town, South

Africa

${ }^{2}$ Exercise Science and Sports Medicine, South African Medical Research Council and University of Cape Town, Newlands, South Africa

\section{Correspondence to}

Ross Tucker, Department of Human Biology, University of Cape Town, Exercise Science and Sports Medicine, Cape

Town, P0 Box 115, Newlands,

7725, South Africa;

ross.tucker@mweb.co.za

Received 1 September 2011 Accepted 6 March 2012

Published Online First

25 April 2012

\section{ABSTRACT}

Elite sporting performance results from the combination of innumerable factors, which interact with one another in a poorly understood but complex manner to mould a talented athlete into a champion. Within the field of sports science, elite performance is understood to be the result of both training and genetic factors. However, the extent to which champions are born or made is a question that remains one of considerable interest, since it has implications for talent identification and management, as well as for how sporting federations allocate scarce resources towards the optimisation of high-performance programmes. The present review describes the contributions made by deliberate practice and genetic factors to the attainment of a high level of sporting performance. The authors conclude that although deliberate training and other environmental factors are critical for elite performance, they cannot by themselves produce an elite athlete. Rather, individual performance thresholds are determined by our genetic make-up, and training can be defined as the process by which genetic potential is realised. Although the specific details are currently unknown, the current scientific literature clearly indicates that both nurture and nature are involved in determining elite athletic performance. In conclusion, elite sporting performance is the result of the interaction between genetic and training factors, with the result that both talent identification and management systems to facilitate optimal training are crucial to sporting success.

\section{INTRODUCTION}

Considerable research exists on the roles played by both genetic factors and training in determining elite sporting performance. The dismissal of either genetic or training factors to performance is anathema in sports science, since considerable evidence exists to distinguish elite athletes from less well-performing athletes with respect to both genetic factors and training histories. However, the polarisation of this debate has recently become prominent in the popular literature, with at least three books devoted to advocating the theory that it is deliberate training, and not genetics, that produces champions.

The 'born versus bred' question dates back to the 1800s, and the theory of Sir Francis Galton which posited that mental capacities are limited by hereditary factors (Galton 1869, quoted in ${ }^{1}$ ). The Galtonian model proposed that practice and training would lead to improvements in performance, but that a ceiling existed for each person, influenced by heritable characteristics. ${ }^{1}$ In contrast, Ericsson and others ${ }^{1-3}$ have suggested that performance is constrained not by genetic or innate factors, but by engagement in deliberate practice and training during optimal periods of development. According to this model, practice is both necessary and sufficient for the attainment of deliberate performance, and is effective because it 'selectively activates dormant genes that are contained within all healthy individuals' DNA'.1 Ericsson has however, neither produced any evidence of which genes these may be, nor has he established that training activates genes to the same extent when comparing individuals. Rather, his model is based on studies using retrospective questionnaires of training history, in skill-based activities including darts and violin playing, and overlooks a body of scientific literature which strongly disproves his model. ${ }^{14}$

Within the sports sciences, elite performance is understood to be the result of both training and genetic factors, as illustrated by models such as those proposed by Vaeyens et $a l^{5}$ and Schneider. ${ }^{6}$ However, whether champions are born or made is a question that remains of considerable interest in the exercise sciences, since it has implications for talent identification and management, as well as for how sporting federations allocate scarce resources towards the optimisation of high-performance programmes.

The present review aims to describe the contributions made by deliberate practice and genetic factors to the development of elite performance. We recognise that considering genetic and practice effects in isolation is unlikely to yield a satisfactory answer to a complex question. However, in order to develop a systematic understanding of the interaction between inherited and trainingrelated factors, we separately evaluate the two opposing theories for performance, beginning with the model of deliberate practice, followed by a brief review of the key genetic factors that inform our understanding of elite sporting performance.

\section{THE DELIBERATE PRACTICE MODEL FOR EXPERT PERFORMANCE}

The model for deliberate practice, as proposed by Ericsson et al, ${ }^{12}$ holds that 'the distinctive characteristics of exceptional performers are the result of adaptations to extended and intense practice activities that selectively activate dormant genes that are contained within all healthy individuals' DNA'. ${ }^{1}$

Central to this theory is that elite performance is achievable for any individual, and is constrained primarily by the 'engagement in deliberate practice 
and the quality of the available training resources'. ${ }^{1}$ Ericsson has further developed this model to propose that a specific volume of $10000 \mathrm{~h}$ of training must be accumulated over a period of approximately 10 years of structured training and involvement in an activity in order to achieve expert levels. ${ }^{47}$

The seminal study that led to the development of the deliberate practice framework and the $10000 \mathrm{~h}$ concept was conducted on violinists in Berlin, where it was found that the subjectively judged skill level of the violinists was associated with accumulated training time during the first 20 years of their lives. ${ }^{2} 4$ That is, the best expert performers had accumulated just over $10000 \mathrm{~h}$ by the age of 20 . In contrast, those violinists judged to be good or average had accumulated only approximately 7800 and 4600 h, respectively. Ericsson concluded that there was 'complete correspondence between the skill level of the group and their average accumulation of practice time alone with the violin'. ${ }^{2}$

Crucially, however, Ericsson presented no measures of variance in the results in this study. ${ }^{2}$ That is, no SD or ranges were provided, and as such, it is unclear whether the association between training and performance applies to every individual. It must be emphasised that individual variation within groups is of crucial significance. An individual who is able to achieve best expert levels can, according to this model, do so only if they engage in sufficient deliberate practice. Similarly, the theory predicts that an individual who fails to attain expert levels must fail because they have not accumulated the required training time. Any individual who violates either of these conditions, either by achieving best expertise with less time or by failing to achieve expert levels despite exceeding the training volume of peers, call into question the theory that posits that performance is the result of selective activation of DNA possessed by all individuals.

As such, studies of sporting performance that have examined variability are of considerable value. The Gronigen talent studies on soccer, hockey, basketball, tennis and gymnastics have clearly shown that talent identification requires an individualised approach, since individual development curves differ so significantly from one another. ${ }^{7-9}$

This is further shown in studies of chess performance. ${ }^{10}$ In one study, accumulated training time to reach master level in a group of 104 chess players was $11053 \pm 5538$ h (mean \pm SD), in close agreement with the average time in the violin study. ${ }^{2} 10$ However, enormous differences existed between individuals, as indicated by the SD and coefficient of variation (50\%). The fastest player to reach master level had done so after only $3016 \mathrm{~h}$, while another had taken $23608 \mathrm{~h}$. Other players in the sample had failed to achieve master level despite accumulating over $25000 \mathrm{~h}$ of practice. Variables including practice time could account for only $34 \%$ of the variance in performance rating, and it was concluded that practice, while important for performance, was not sufficient for becoming a master.

Similarly, darts performance has been found to be poorly related to deliberate practice time, with only $28 \%$ of the variance in performance explained by accumulated practice time despite the accumulation of 12839 h of practice over 15 years. ${ }^{3}$ It must be noted that there is scope for disputing the large ranges of practice on the basis that a given hour of practice is not necessarily equal. Ericsson has spoken of and defined 'deliberate practice' as 'practice activities with full concentration on improving some specific aspect of performance'. ${ }^{1}$ For sport in particular, the wide scope of training activities may not be easily quantifiable, and there will be dispute over whether an hour of practice on one aspect of performance (for example, strength training) is as effective as another (tactical or skill training), or whether the individual is using 'full concentration' during practice. However, it must also be noted that this theory, in its current form, is unfalsifiable, since the quality of practice can always be questioned to explain why the quantity of practice does not conform to some requisite number, in this case, $10000 \mathrm{~h}$. However, the chess and darts studies clearly reveal a large range of required hours, and sports examples discussed subsequently show the role of genetic factors in moderating both the response to training and the ultimate performance level reached.

These studies of skill-based activities challenge the theory that performance is constrained by accumulated hours of deliberate practice. Studies of sport reveal that elite athletes rarely complete $10000 \mathrm{~h}$ before reaching international levels. ${ }^{11} 12$ For example, $28 \%$ of elite Australian athletes reached elite status within 4 years of taking up the sport for the very first time, ${ }^{13}$ while international level wrestlers, field hockey players and footballers had accumulated only $6000 \mathrm{~h}, 4000 \mathrm{~h}$ and 5000 h of training, respectively. ${ }^{1415}$

A systematic approach to talent identification and training has also been able to produce a world-class skeleton athlete within 10 weeks of first exposure to the sport. ${ }^{16}$ Athletes were chosen based on sprint performance, anthropometrical characteristics and power, which favoured individuals with prior training in other sports. A period of training followed, and athletes were able to achieve top six rankings in international competition and Olympic participation within 14 months, 'leap-frogging' more experienced competitors. ${ }^{16}$ It was concluded that talent transfer, based on innate abilities and ability developed through playing other sports, can be used to accelerate the acquisition of expert performance into very short time frames, which explains why elite athletes often perform significantly less than $10000 \mathrm{~h}$ of deliberate practice. ${ }^{13} 16$

Also of note is the finding that the best performing young footballers who will go on to play the sport professionally display superior dribbling skills, endurance capacity and tactical awareness compared to their peers, from as early as 14 years of age. ${ }^{917}$ These differences appear well before it is possible to accumulate $10000 \mathrm{~h}$ of practice, but allow predictions of which players will go on to achieve best performances in adulthood, suggesting that the effectiveness of and response to training, rather than simply training, determines success. The factors responsible for differences in training adaptability are not known, but genetic factors seem likely, as will be described subsequently.

It is clear that the theory that expert level performance is the result of deliberate practice alone fails to account for the wide range of individual performance levels and responses to training observed in sport and skill-based activities like chess and darts. Indeed, the finding that only $34 \%$ and $28 \%$ of the variance in performance can be explained by practice in chess and darts, respectively, should be sufficient to discard any theory that hypothesises that performance is 'primarily constrained' by an individual's engagement in deliberate practice ${ }^{1}-$ this is clearly not the case, and other factors, which have not been elucidated in those studies, ${ }^{310}$ must also influence performance.

In conclusion, the deliberate practice model for performance has contributed to our understanding that skill and certain aspects of physiological performance can be significantly improved as a result of deliberate practice. However, this model has failed to demonstrate that expert performance levels are achievable for any and every individual, since large individual differences in performances achieved through training have 
been documented. This invites discussion of the possibility that genetic differences between individuals are also crucial to sporting performance.

\section{THE GENETIC INFLUENCE ON PERFORMANCE}

At the biological level, numerous physiological and biochemical systems and pathways must interact and function optimally to enable elite performances. These include physiological and biochemical processes within the musculoskeletal, cardiovascular, central nervous and respiratory systems. The optimal biological characteristics are sport-specific - the advantageous properties of skeletal muscle are very different for an endurance athlete compared with a sprint or power athlete, for example.

When considered individually, each biological system is in its own right complex, consisting of different cell types, proteins and other macromolecules. Multiple protein-coding and non-coding genes located throughout the entire human genome determine the genetic blueprint for each individual biological system. With these layers of complexity from the whole body right down to the genetic material in each cell, it is highly unlikely that a single or even a few genetic elements are associated with superior athletic performance.

It is therefore incorrect to cite the failure to discover a candidate gene that can be conclusively linked to performance ${ }^{1819}$ as evidence that genetics play only a minimal, or even no role, in the attainment of elite performance. Although few would dispute that practice and training resources are crucial to the attainment of a higher level of performance, it is generally accepted by the scientific community that both environmental and genetic factors determine an individual's athletic ability. 52021

\section{GENETIC COMPLEXITY AND GENETIC DETERMINANTS OF PERFORMANCE}

Elite performance is a polygenic trait. ${ }^{22}$ The genes that have been associated with performance or performance-related phenotypes to date have been extensively reviewed. ${ }^{22}$ Generally speaking, different sets of genetic sequence variants have been associated with endurance performance and sprint/power events. Although, investigators have primarily investigated the association of common variants with performance, the role of rare and other DNA variants, such as copy-number variants (CNV), also need to be considered when investigating performance or performance-related phenotypes. ${ }^{23}$ The role of rare and CNV in determining athletic performance is however beyond the scope of this review.

Rather than merely listing and describing specific genes that have been associated with performance and performancerelated traits, we will discuss the current knowledge of the role that genes play in determining four of the many intrinsic traits known to contributes to elite performance phenotypes. These are sex, height, skeletal muscle properties and $\mathrm{VO}_{2} \max$ (figure 1). As mentioned, not all of these traits necessarily affect performance in all sporting codes or to the same extent, but they illustrate the complexity of genetic factors on single phenotypic traits, and thus on the complexity of exercise performance.

\section{Sex}

While inherently obvious, biological sex is a key predictor of absolute levels of performance, and is the most fundamental biological characteristic where genes influence performance. An analysis of world record performances in the track and road running events, ranging from the $100 \mathrm{~m}$ to a $90 \mathrm{~km}$ ultramarathon, highlights that the best males out perform the best females by between $9 \%$ and $14 \% .{ }^{24}$ The current women's marathon world best time, for example, lies outside the top 3000 performances in the marathon's history. ${ }^{24}$ Sex therefore plays a significant role in determining elite performance and is the reason that athletes compete in separate male and female categories for most sporting codes. Sex is determined entirely genetically during development, and unless an athlete presents with one of the rare disorders of sex development, ${ }^{25}$ there is no difference between genetic and anatomical sex (figure 1). Although several genes are probably involved in sex development and more specifically involved in ovarian development, the SRY, SOX9 and DHTR genes are the best understood genes involved in the development of the male phenotype. ${ }^{25} 26$

\section{Height}

Unlike sex, height is determined by both genetic and environmental factors such as nutrition, and is the result of several growth and developmental processes (figure 1). Numerous studies report that height is highly heritable with $80 \%$ of its variance controlled by multiple genes (polygenic). ${ }^{27} 28$ The influence of height on performance is of course sport specific - it is a prerequisite for success in sports such as volleyball, basketball and netball, whereas large body size and stature may be deleterious for endurance running, for example. It has however been documented that athletes in many sports have been getting taller, heavier and more slender over time, even when corrected for changes in height and size within the general population. ${ }^{29}$ Some talent identification programmes, such as the UK's Tall and Talented programme, adopt height as an initial screening variable for prospective Olympic athletes (http://www.uksport. gov.uk/pages/talent-2016-tall-and-talented/; accessed on 23 August 2011). A discussion of the genetic determinants of height is thus relevant, for it illustrates (a) the genetic complexity of a relatively simple phenotype like height, further highlighting the complexity of identifying a performance gene, and (b) how genetic factors may predispose an individual for success or mitigate against it based on their stature.

Meta-analysis of genome-wide association studies (GWAS) has identified 47 common genetic variants, which only explain $5 \%$ of height in Caucasians. ${ }^{28}$ Recently, Yang et al ${ }^{30}$ estimated that approximately 295000 common single nucleotide polymorphisms (SNPs) explained $45 \%$ of the variance in height within 3925 unrelated individuals using linear model analysis. They also suggested that the remaining $35 \%$ of the variance determined by genetics could be explained by the incomplete linkage disequilibrium between the causal variants and the genotyped SNPs. Rare genetic variants may however also account for a significant fraction of the 'missing heritability' in height. The implication of this finding is that height, a relatively easily measurable trait, is the outcome of small contributions of thousands of sequence variants within genes involved in the growth and developmental processes, which ultimately determine height. Significantly, athletic performance is undoubtedly more complex than height, and if such a large population and almost 300000 SNPs are able to account for only $45 \%$ of the variance in height, then the concept that a single gene, or even a few thousand genes, can explain athletic performance is grossly oversimplified and may ultimately be futile.

\section{$\mathrm{VO}_{2}$ max}

Recently, Ericsson ${ }^{1}$ challenged the contribution made by genetic factors to the attainment of elite athletic performance by specifically focusing on $\mathrm{VO}_{2}$ max and muscle-fibre type heritability, and concluded that neither is a good trait that may 


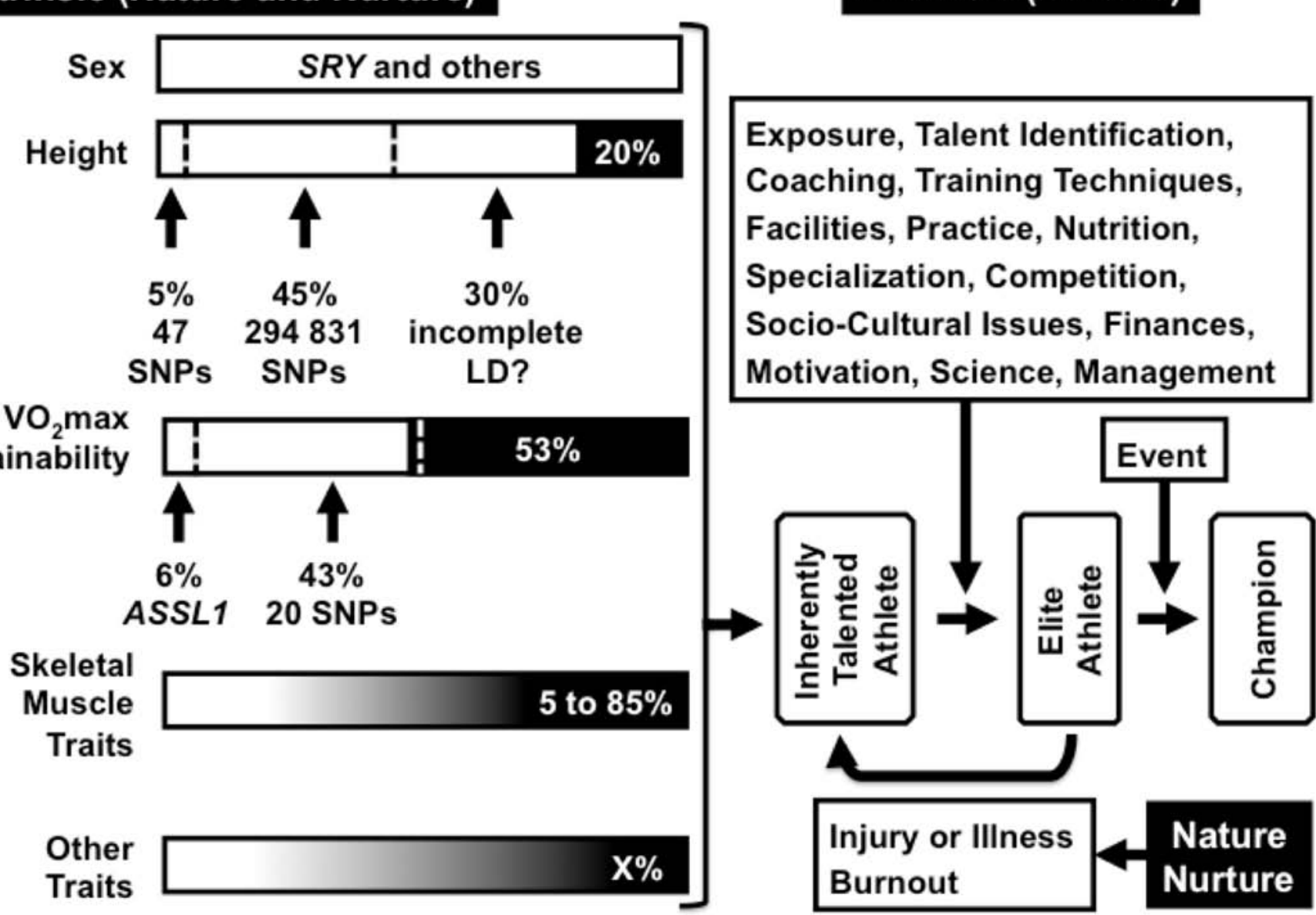

Figure 1 The complex relationship between intrinsic (nature and nurture) and extrinsic factors (nurture) that determine elite athletic performance. Only the four intrinsic factors described in this review are identified as rectangular bars on the left of the figure. The fifth bar labelled as other traits represents the numerous other intrinsic factors, which contribute to determining elite performance, not described in this review. Many of the intrinsic factors are within their own right complex phenotypes determined by both nature (white shading) and nurture (black shading). Sex (male) differentiation is totally controlled by genes such as SRY, SOX9 and DHTR and is represented entirely by white shading. Height and $\mathrm{VO}_{2}$ max trainability are determined by both genes (relative contribution is in white shading) and the environment, as indicated by black shading. The number of SNPs, which contributes together with the relative contribution towards the trait is indicated. Six percent of $\mathrm{VO}_{2}$ max trainability appears to be determined by a single gene, the ASSL1 gene. The large range within the literature indicating the genetic and environmental contributions to skeletal muscle traits is indicated by the grey shading transition from the white (genetic contribution) to black (environment contribution) shading. The correct combination of intrinsic factors will determine an inherently talented athlete. Inherently talented athletes must be exposed to the correct combination of the listed and other extrinsic factors to become an elite athlete. Winning an elite athletic event produces a champion. Exposure of athletes to extrinsic factors can result in injury, illness or burnout. Musculoskeletal soft tissue injuries for example are also complex phenotypes determined by both genetic and environmental factors. ${ }^{40}$

be 'constrained by heredity'. However, this conclusion' ${ }^{1}$ fails to acknowledge a vast body of research that has established relationships between genetic factors and these two exerciserelated phenotypes.

For example, studies in which a large cross-section of individuals has been exposed to a standardised training program have found large individual differences in $\mathrm{VO}_{2} \mathrm{max}$. Collectively, the Heritage studies, ${ }^{31} 32$ the Dose Response to Exercise in Women (DREW) study ${ }^{33}$ and SSTRIDE studies ${ }^{34}$ have found an average training-induced improvement in $\mathrm{VO}_{2}$ max of $15.2 \pm 9.7 \%$, but the interindividual differences are significant. For example, approximately one in seven individuals $\left(14 \%\right.$ ) improved $\mathrm{VO}_{2}$ max by less than $200 \mathrm{ml} / \mathrm{min}$ (less than $8 \%$ improvement compared to baseline). In contrast, $8 \%$ of the population improved by more than $700 \mathrm{ml} / \mathrm{min}$ (a $28 \%$ improvement). ${ }^{31}$
Both genetic and environmental factors have been reported to determine the $\mathrm{VO}_{2}$ max in the untrained state and in response to training. Approximately $50 \%$ of these two $\mathrm{VO}_{2}$ max traits are heritable. ${ }^{35}$ Genomic scans have identified markers on chromosomes 4, 8, 11 and 14 that are linked to $\mathrm{VO}_{2} \max$ in the untrained state, while a different set of markers on chromosomes 1, 2, 4, 6 and 11 were linked to $\mathrm{VO}_{2}$ max trainability. ${ }^{35}$ Using GWAS with a panel of \pm 325000 SNPs, 21 of the SNPs were found to account for $49 \%$ of the trainability in $\mathrm{VO}_{2} \max$ (figure 1). One of the SNPs located within the acyl-coenzyme synthase long chain number 1 gene accounted (albeit mathematically) for $6 \%$ of the training response. ${ }^{31}$

Significantly, individuals who carried nine or fewer of the previously mentioned 21 SNPs were found to have improved by less than $221 \mathrm{ml} / \mathrm{min}$, whereas individuals who carried 19 or more of these alleles had improved by an average of 604 


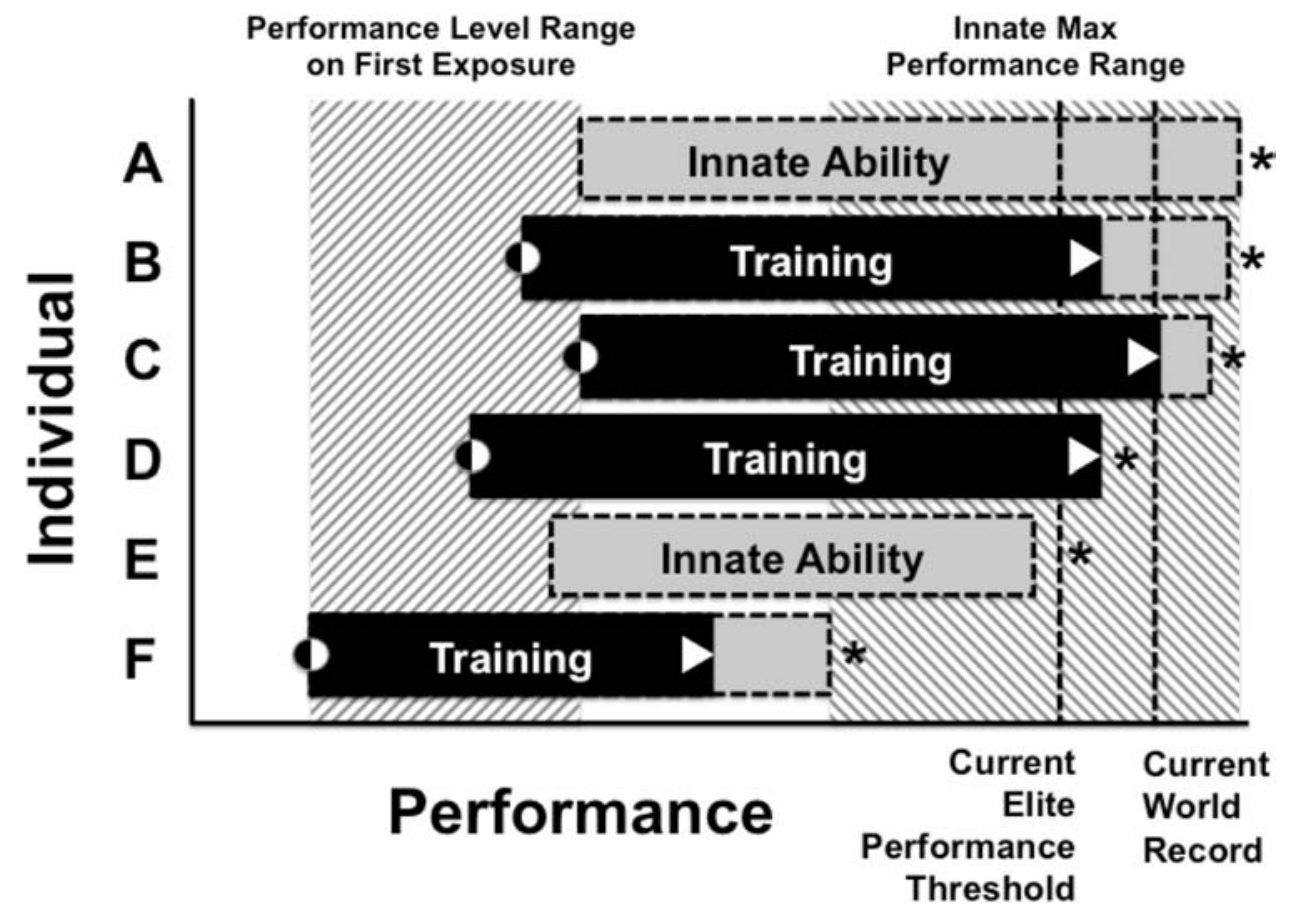

Figure 2 A theoretical illustration of the combined effects of nurture (black rectangles) and nature (grey rectangles) on the actual and potential sporting performance level of six injury free, healthy subelite and elite individuals ( $A$ to $F)$. In this model, training is defined as the process by which genetic potential is realised. Two individuals ( $A$ and $E$ ) are not athletes or have not participated in the sport, while the remaining four individuals $(B, C, D$ and $F$ ) actively train and participate in the sport. The initial performance level on first exposure to the sport, and the current performance of the four athletes are indicated by black-white circles and white triangles, respectively. The asterisk indicates the maximum performance threshold of all individuals. There are interindividual differences between the actual $(B, C, D$ and $F)$ and potential $(A$ and $E)$ starting performances of the individuals, which are determined by both nature and nurture. There are also interindividual differences between the maximum performance thresholds of all six individuals, which are determined genetically. ${ }^{21}$ There is not necessarily a tight positive correlation between the athlete's starting and maximum threshold performances. Dashed lines indicate the hypothetical elite performance threshold and current world record. Although athlete $\mathrm{D}$ would be considered elite, he or she has reached a maximum performance threshold through training, and further improvements are not possible. Athlete $C$ is the current world record holder but retains the capacity for improvement (grey box) and the ability to further improve the world record. However elite athlete $B$, whose current performance level is lower than athlete $C$, also has the potential to break the current world record. Elite athlete B is also potentially a better athlete the current world record holder (athlete C).

$\mathrm{ml} / \mathrm{min} .{ }^{31}$ Clearly, the presence of certain SNPs has a strong influence on the response to training, which contradicts the conclusion made by Ericsson, ${ }^{1}$ and suggests a very powerful role for genes in performance.

\section{Skeletal muscle}

Skeletal muscle is a highly adaptable tissue responding positively to exercise but negatively to ageing, disuse and disease. ${ }^{36}$ Skeletal muscle can be characterised by several traits. For the purposes of this review, these traits will be divided into (1) muscle mass and strength and (2) muscle power and metabolism. Although a large range, from 15 to over $90 \%$, has been reported, all studies have shown that muscle mass and strength has a heritable component (figure 1). ${ }^{36}$ Less data is available for the heritability of muscle anaerobic power, which ranges from $46 \%$ to $84 \%$. Although heritability values of nearly $50 \%$ have been documented, it has also been reported that the environment plays the predominant role in the aerobic capacity of skeletal muscle. ${ }^{36}$

\section{CONCLUSIONS}

Given the enormous complexity of genotype-phenotype relationships and the complexity of the human genome, it is perhaps not surprising that a candidate gene approach has not been able to successfully identify all the genetic variants associated with performance. Considering that approximately
295000 SNPs explain only $45 \%$ of the variance in height, ${ }^{30}$ it is clear that performance, arguably a far more complex variable than height, may require enormous sample sizes and a staggeringly large number of SNPs and other types of genetic polymorphisms before it becomes possible to fully understand and appreciate the contribution inheritance plays in elite performance. Although case-control genetic association studies have played an important role in starting to understand the specific details of the heritability of performance, the field needs to move beyond this approach if it wants to unravel the complex interaction between genes and the environment in determining athleticism.

Although not a focus of this review, further complexity within genomics is found in the concept of epigenetics, which refers to heritable alterations in chromosome function or gene expression caused by mechanisms other than changes in DNA sequence. It has recently been reported that exercise causes epigenetic changes that lead to improved memory and coping mechanisms in response to stress within rats. ${ }^{37}$ The potential role that epigenetic mechanisms may play in contributing to superior performance remains to be determined. In addition, although the focus of research on the genetics of performance and related phenotypes to date has been on the protein-coding genes, the likely role of non-protein genes such as miRNAs in contributing to performance phenotypes also needs to be investigated. ${ }^{38}$ 


\section{SUMMARY}

It is not presently possible to ascertain the exact relative contribution of either genes or training to elite sporting performance, and it must be recognised that it is likely that the relative importance of training may differ for different sports, such that in some sports, genetic factors may be more significant. However, in the present review, we have attempted to illustrate that within identified biologically influenced variables such as $\mathrm{VO}_{2}$ max and muscle function, there is considerable variation between individuals, in the initial performance capacity, and in the adaptations that occur in response to training. This variation is linked to genetic factors, down to the level of identified SNPs, such that individuals with different genetic variants will display a phenotype favouring the attainment of elite performance.

Scientific data on other determinants of exercise performance, including metabolic efficiency, fuel-oxidation rates, muscle-fibre contractility, motor skill acquisition and even motivation for exercise ${ }^{39}$ are currently limited, but it seems reasonable to suggest that these characteristics too will be influenced by genes and gene variants.

The essential role of practice and training has also been recognised in the present review. However, we suggest that the concept of a minimum volume of training required for expert performance, and in particular the concept of $10000 \mathrm{~h}$, is flawed, based on the body of evidence suggesting that among individuals who have achieved similar performance levels (those in the elite group, for example), training times are rarely similar. Further, the concept of talent transfer suggests that a more broad view of training and practice may be required for certain sports, whereby specialised training in one domain is not required.

This does not negate the value of training, and so we propose a model where training is defined as the realisation of genetic potential. This is illustrated in figure 2, where six hypothetical cases are provided of individuals who either never participate in training for a particular sport (figure $2 \mathrm{~A}, \mathrm{E}$ ), or who train in order to improve performance up to a performance threshold that is unique for each individual, and which is determined by an interaction between genes, training and the environment (figure $2 \mathrm{~B}-\mathrm{D}, \mathrm{F}$. See also figure 1). Crucially, individuals differ with respect to their starting performance level on first exposure to the sport, and in their response to training, such that the final performance level differs between individuals. This accounts for why similar practice volumes result in large performance differences, and for how elite sporting performance can be achieved with relatively low training volumes.

We also suggest that this model, where training maximises the likelihood of obtaining a performance level with a genetically controlled 'ceiling', accounts for the observed dominance of certain populations in specific sporting disciplines. However, future work is required to elucidate the biological processes that may be associated with these potential differences. In conclusion, elite sporting performance is the result of the interaction between genetic and training factors, with the result that both talent identification and management systems to facilitate optimal training are crucial to sporting success. The traditional methods used by coaches for talent identification should be used before any genetic testing, because performance is multifactorial and therefore there is always the possibility that the genetic profile, no matter how detailed, may miss a crucial DNA variant or non-genetic factor that enhances performance.
Acknowledgements The authors would like to acknowledge the contribution of David Epstein to the concepts reviewed in the manuscript.

Competing interests None.

Provenance and peer review Not commissioned; externally peer reviewed.

\section{REFERENCES}

1. Ericsson KA, Nandagopal K, Roring RW. Toward a science of exceptional achievement: attaining superior performance through deliberate practice. Ann N Y Acad Sci 2009;1172:199-217.

2. Ericsson $\mathbf{K}$, Krampe R. The role of deliberate practice in the acquisition of expert performance. Psychol Rev 1993;100:363-406.

3. Duffy L, Baluch B. Dart performance as a function of facets of practice amongst professional and amateur men ana women players. Int J Sport Psychol 2004;35:232-45.

4. Ericsson KA. The Cambridge handbook of expertise and expert performance. Cambridge University Press 2006.

5. Vaeyens R, Güllich A, Warr CR, et al. Talent identification and promotion programmes of Olympic athletes. J Sports Sci 2009;27:1367-80.

6. Schneider $\mathbf{W}$. The impact of expertise on performance: illustrations from developmental research on memory and sports. High Ability Stud 1997;8:7-18.

7. Elferink-Gemser MT, Jordet G, Coelho-E-Silva MJ, et al. The marvels of elite sports: how to get there? Br J Sports Med 2011;45:683-4.

8. Phillips E, Davids K, Renshaw I, et al. Expert performance in sport and the dynamics of talent development. Sports Med 2010;40:271-83.

9. Huijgen BC, Elferink-Gemser MT, Post WJ, et al. Soccer skill development in professionals. Int J Sports Med 2009;30:585-91.

10. Gobet $\mathbf{F}$, Campitelli $G$. The role of domain-specific practice, handedness, and starting age in chess. Dev Psychol 2007; 43:159-72.

11. Gibbons $\mathbf{T}$, Hill R, McConnell A, et al. The path to excellence: a comprehensive view of development of U.S. Olympians who competed from 1984-1998. United States Olympic Committee 2002.

12. Baker J, Côté J, Deakin J. Expertise in ultra-endurance triathletes early sport involvement, training structure, and the theory of deliberate practice. J App/ Sport Psychol 2005; 17:64-78.

13. Oldenziel $\mathbf{K}$, Gagne F. Factors affecting the rate of athlete development from novice to senior elite: How applicable is the 10-year rule. Athens 2004: Pre-olympic Congress Sport Science Through the Ages: challenges in the New Millennium. Athens, 2004.

14. Hodges NJ, Starkes JL. Wrestling with the nature of expertise: a sport specific test of Ericsson, Krampe and Tesch-Römer's (1993) theory of "deliberate practice". Int J Sport Psychol 1996;27:400-24.

15. Helsen WF, Starkes JL, Hodges NJ. Team sports and the theory of deliberate practice. J Sport Exerc Psychol 1998;20:12-34.

16. Bullock N, Gulbin JP, Martin DT, et al. Talent identification and deliberate programming in skeleton: ice novice to Winter Olympian in 14 months. J Sports Sci 2009;27:397-404

17. Roescher CR, Elferink-Gemser MT, Huijgen BC, et al. Soccer endurance development in professionals. Int J Sports Med 2010;31:174-9.

18. Macarthur DG, North KN. Genes and human elite athletic performance. Hum Genet 2005;116:331-9.

19. Scott RA, Wilson RH, Goodwin WH, et al. Mitochondrial DNA lineages of elite Ethiopian athletes. Comp Biochem Physiol B, Biochem Mol Biol 2005;140:497-503.

20. Vaeyens R, Lenoir M, Williams AM, et al. Talent identification and development programmes in sport: current models and future directions. Sports Med 2008;38:703-14.

21. Tucker R, Collins M. Athletic performance and risk of injury - Can genes explain all? Dialog Cardiovasc Med (In Press).

22. Rankinen T, Roth SM, Bray MS, et al. Advances in exercise, fitness, and performance genomics. Med Sci Sports Exerc 2010;42:835-46.

23. Lupski JR, Belmont JW, Boerwinkle E, et al. Clan genomics and the complex architecture of human disease. Cell 2011;147:32-43.

24. Tucker $\mathbf{R}$, Collins $M$. The science of sex verification and athletic performance. Int J Sports Physiol Perform 2010;5:127-39.

25. Kousta E, Papathanasiou A, Skordis N. Sex determination and disorders of sex development according to the revised nomenclature and classification in 46,XX individuals. Hormones (Athens) 2010;9:218-131.

26. Arboleda VA, Vilain E. The evolution of the search for novel genes in mammalian sex determination: from mice to men. Mol Genet Metab 2011;104:67-71.

27. Weedon MN, Frayling TM. Reaching new heights: insights into the genetics of human stature. Trends Genet 2008;24:595-603.

28. Lettre G. Genetic regulation of adult stature. Curr Opin Pediatr 2009;21:515-22.

29. Charles JD, Bejan A. The evolution of speed, size and shape in modern athletics. $J$ Exp Biol 2009;212:2419-25.

30. Yang J, Benyamin B, McEvoy BP, et al. Common SNPs explain a large proportion of the heritability for human height. Nat Genet 2010;42:565-9. 
31. Bouchard C, Sarzynski MA, Rice TK, et al. Genomic predictors of the maximal 02 uptake response to standardized exercise training programs. J Appl Physiol 2011:110:1160-70

32. Bouchard C, Leon AS, Rao DC, et al. The HERITAGE family study. Aims, design, and measurement protocol. Med Sci Sports Exerc 1995;27:721-9.

33. Morss GM, Jordan AN, Skinner JS, et al. Dose response to exercise in women aged 45-75 yr (DREW): design and rationale. Med Sci Sports Exerc 2004;36:336-44

34. Kraus WE, Torgan CE, Duscha BD, et al. Studies of a targeted risk reduction intervention through defined exercise (STRRIDE). Med Sci Sports Exerc 2001;33:1774-84.

35. Bouchard C, Rankinen T, Chagnon YC, et al. Genomic scan for maximal oxygen uptake and its response to training in the HERITAGE Family Study. J App/ Physiol 2000;88:551-9.
36. Stewart CE, Rittweger J. Adaptive processes in skeletal muscle: molecular regulators and genetic influences. J Musculoskelet Neuronal Interact 2006:6:73-86.

37. Collins A, Hill LE, Chandramohan $Y$, et al. Exercise improves cognitive responses to psychological stress through enhancement of epigenetic mechanisms and gene expression in the dentate gyrus. PLOS ONE 2009; 4:e4330.

38. Roth SM. MicroRNAs: playing a big role in explaining skeletal muscle adaptation? J Appl Physiol 2011:110:301-2.

39. Knab AM, Lightfoot JT. Does the difference between physically active and couch potato lie in the dopamine system? Int J Biol Sci 2010;6:133-50.

40. Collins M, Raleigh SM. Genetic risk factors for musculoskeletal soft tissue injuries. Med Sport Sci 2009:54:136-49. 